\title{
Perilaku Etis Mahasiswa Akuntansi Ditinjau dari Locus of Control dan Love of Money
}

\author{
Ni Nyoman Sri Rahayu Trisna Dewi* \\ Fakultas Bisnis, Universitas Triatma Mulya, Indonesisa
}

Ethical behavior is related to self-control. A person who is able to control himself will not easily carry out unethical actions intentionally. Ethical violations committed by someone can also be based on a factor of money. Someone who to love with money will tend to do various ways to meet their needs, even though they deviate from ethical behavior. This study aimed at determine the effect of locus of control and love of money on the ethical behavior of accounting students at the Faculty of Business, Triatma Mulya University. This study used a saturated sampling method, so that the number of samples obtained is 38 students. The analysis technique used in this research was multiple regression analysis. The results showed that locus of control had a positive effect on the ethical behavior of the accounting students of the Faculty of Business, Triatma Mulya University, while love of money had no effect on the ethical behavior of accounting students at the Faculty of Business, Triatma Mulya University.

Keywords: Locus of Control, Love of Money, Ethical Behavior

OPEN ACCESS

ISSN 2548-3501 (online)

Edited by:

Eny Maryanti

Reviewed by:

Rina T.

*Correspondence:

Ni Nyoman Sri Rahayu Trisna Dewi

rahayutrisna333@gmail.com

Received: 15 Juni 2019

Accepted: 5 Juli 2019

Published: 31 Juli 2019

Citation:

NNSRTD (2019) Perilaku Etis

Mahasiswa Akuntansi Ditinjau dari

Locus of Control dan Love of

Money.

Journal of Accounting Science. 3:2.

doi: 10.21070/jas.v3i2.2468
Perilaku etis berkaitan dengan pengendalian diri seseorang. Seseorang yang mampu mengendalikan diri tidak akanmudah melakukan perbuatan tidak etis dengan sengaja. Pelanggaran etika yang dilakukan oleh seseorang juga dapat didasari oleh faktor uang. Seseorang yang memiliki love of money yang tinggi akan cenderung melakukan berbagai cara untuk memenuhi kebutuhannya, meskipun menyimpang dari perilaku etis. Penelitian ini bertujuan untuk mengetahui pengaruh locus of control dan love of money terhadap perilaku etis mahasiswa akuntansi Fakultas Bisnis Universitas Triatma Mulya.Penelitian ini menggunakan metode sampling jenuh, sehingga diperoleh jumlah sampel sebanyak 38 mahasiswa.Teknik analisis yang digunakan adalah analisis regresi berganda. Hasil penelitian menunjukkan bahwa locus of control berpengaruh positif terhadap perilaku etis mahasiswa akuntansi Fakultas Bisnis Universitas Triatma Mulya, sedangkan love of money tidak berpengaruh terhadap perilaku etis mahasiswa akuntansi Fakultas Bisnis Universitas Triatma Mulya.

Keywords: Locus of Control, Love of money, Perilaku Etis 


\section{PENDAHULUAN}

Akuntansi merupakan suatu disiplin ilmu yang sering berkaitan dengan keuangan.Pengelolaan keuangan sangat riskan menjadi objek dilakukannya kecurangan.Demikian juga dengan para akuntan yang bidang pekerjaannya berada dalam lingkup akuntansi, baik akuntan publik, akuntan perusahaan swasta maupun akuntan pemerintahan. Akuntan akan selalu menjadi sorotan bagi masyarakat jika terjadi suatu kecurangan ataupun pelanggaran yang berkaitan dengan keuangan. Seorang akuntan harus memiliki perilaku yang etis agar dapat terhindar dari permasalahan mengenai keuangan.Perilaku etis seorang akuntan tidak muncul begitu saja saat melakoni pekerjaan di bidang akuntansi, namun harus dipupuk semenjak dini.Seseorang yang memutuskan untuk menjadi seorang akuntan seharusnya sudah memfokuskan tujuannya tersebut semenjak bangku kuliah.Oleh sebab itu sangat penting menumbuhkan perilaku etis para akuntan semenjak masih menjadi mahasiswa, khususnya mahasiswa akuntansi.

Yusuf and Anim (2015) menyatakan pekerjaan akuntan harus dilakukan dengan sikap profesional sepenuhnya berdasarkan standar moral dan etika yang berlaku.Akuntan yang memiliki sikap profesional akan dapat menghadapi tekanan yang timbul dari dirinya sendiri atau dari pihak eksternal. Kemampuan akuntan untuk dapat memahami dan peka terhadap masalah etika juga sangat dipengaruhi oleh lingkungan, salah satunya adalah lingkungan pendidikan. Febrianty (2010) menyatakan Etika meliputi suatu proses penentuan yang kompleks tentang apa yang harus dilakukan seseorang dalam situasi tertentu. Proses tersebut meliputi penyeimbangan sifat sisi dalam (inner) dan sisi luar (outer) yang dibentuk oleh kombinasi unik dari pengalaman dan pembelajaran masing-masing individu.

Himmah (2013) menyatakan perilaku tidak etis pada bidang profesi akuntansi sudah menjadi isu terhangat di kalangan masyarakat luas.Kasus-kasus mengenai skandal keuangan yang terjadi pada perusahaan swasta maupun lembaga pemerintahan tidak dapat dilepaskan dari campur tangan para profesi akuntan.Kasus Enron merupakan salah satu kasus besar yang melibatkan akuntan KAP Arthur Andersen, dimana akuntan KAP Arthur Andersen adalah auditor sekaligus konsultan manajemen Enron.Dalam kasus tersebut akuntan KAP Arthur Andersen ikut membantu Enron memanipulasi laporankeuangan sehingga Enron terlihat sebagai perusahaan yang sehat, padahal senyatanya tidak demikian.Berdasarkan kasus tersebut, seorang akuntan diharapkan memiliki perilaku yang etis sehingga kemungkinan terseretnya akuntan dalam skandal perusahaan-perusahaan besar dapat diminimalisir.

Perilaku etis tidak dapat dilepaskan dari pengendalian diri seseorang. Seseorang yang mampu mengendalikan dirinya tidak akan tergoda untuk melakukan perbuatan yang sudah jelas dinilai tidak etis dengan sengaja. Locus of control adalah cara pandang seseorang terhadap suatu peristiwa apakah dia dapat atau tidak dapat mengendalikan (control) peristiwa yang terjadi pada dirinya. Khoiriyah (2013) menyatakan
Locus of control merupakan persepsi seseorang terhadap siapa yang menentukan nasibnya, dimana persepsi tersebut sangat berpengaruh terhadap perilaku auditor.Locus of control yang dimiliki oleh seseorang dibedakan menjadi locus of control internal dan eksternal.

Orang-orang yang memiliki locus of control internal akan menggunakan kemampuan dan usaha secara dominan. Individu dengan locus of control internal yang mengalami kegagalan akan cenderung menyalahkan dirinya sendiri karena kurangnya usaha yang dilakukan. Sebaliknya individu yang memiliki locus of control eksternal menilai bahwa keberhasilan dan kegagalan adalah bagian dari nasib, oleh karena itu apabila mengalami kegagalan mereka cenderung menyalahkan lingkungan sekitar. Uli et al. (2016) menyatakan auditor yang memiliki locus of control dalam dirinya memiliki perilaku yang dapat mengatasi situasi konflik audit. Semakin tinggi locus of control yang dimiliki seorang auditor maka akan semakin etis perilakunya pada situasi konflik audit. Hal ini berbeda dengan penelitian yang dilakukan oleh Yendrawati and Witono (2011) yang menyatakan bahwa Locus of Control tidak berpengaruh secara signifikan terhadap perilaku etis.

Pelanggaran etika yang dilakukan oleh seseorang, dapat didasari oleh berbagai faktor, salah satunya adalah berkaitan dengan uang (Arshinta et al. (2017) ; Sugiantari and Widanaputra (2016) .Uang dapat mempengaruhi seseorang menjadi dua sisi yang berbeda. Uang dapat menjadi motivasi untuk melakukan hal dengan lebih baik lagi, namun di sisi lain uang juga dapat memotivasi untuk melakukan perbuatan yang tidak etis. Love of money berpandangan bahwa uang adalah motivasi yang dapat mewakili kesuksesan seseorang, oleh karena itu, sikap love of money diperlukan agar seseorang menjadi kaya (Agustini (2016)

Seseorang yang memiliki love of money yang tinggi akan cenderung memandang uang sebagai suatu kebutuhan dan akan berusaha melakukan berbagai cara untuk memenuhinya, meskipun cara yang digunakan menyimpang dari perilaku etis (Bulutobing and Paramitasari (2017) .Persepsi cinta uang yang tinggi akan mengurangi perilaku etis sementara persepsi cinta uang yang rendah akan meningkatkan perilaku etis. Sifat manusia menyebabkan seseorang cenderung selalu memiliki keinginan yang tidak pernah puas dalam suatu pencapaian termasuk keinginan untuk pencapaian finansial (Widiani et al. (2019). Pradanti and Prastiwi (2014) menyatakan seseorang yang memiliki sikap cinta uang berlebih akan cenderung memandang uang sebagai suatu kebutuhan dan berambisi untuk memperolehnya dengan berbagai cara. Nikara and Mimba (2019) menyatakan semakin tinggi hasrat orang memenuhi kebutuhannya dan kecintaannya pada uang, semakin tinggi pula kemungkinan orang tersebut berperilaku tidak etis. Manuari et al. (2018) menyatakan love of money berpengaruh negatif terhadap perilaku etis.Seseorang yang memiliki sikap love of money yang tinggi (menyembah atau mendewakan uang) akan memiliki sikap etika yang rendah. Sebaliknya seseorang yang memiliki cinta uang yang tinggi menyebabkan dia melakukan berbagai 
cara untuk mendapatkan uang, termasuk melanggar kode etik profesionalnya. Basri (2015) menyatakan sifat love of money atau cinta uang yang tinggi akan meningkatkan persepsi etika dalam hal penggelapan pajak.Penelitian ini dilakukan dengan tujuan untuk mengetahui pengaruh locus of control dan love of money secara parsial terhadap perilaku etis mahasiswa akuntansi Fakultas Bisnis Universitas Triatma Mulya

\section{METODE PENELITIAN}

\section{Jenis Penelitian}

Penelitian ini merupakan penelitian kuantitatif yang meneliti sampel atau populasi tertentu.Penelitian ini menguji pengaruh antar variabel independen dan variabel dependen. Variabelvariabel yang akan dianalisis dapat dikelompokkan sebagai berikut:Variabel dependen, yaitu variabel yang dipengaruhi atau yang menjadi akibat, karena adanya variabel independen (Sugiyono (2009). Variabel dependen dalam penelitian ini adalahperilaku etis yang diukur dengan menggunakan indikator sebagai berikut (Nugrahaningsih (2005):

\section{Variabel Dependen,}

Yaitu variabel yang dipengaruhi atau yang menjadi akibat, karena adanya variabel independen (Sugiyono (2009) Variabel dependen dalam penelitian ini adalahperilaku etis yang diukur dengan menggunakan indikator sebagai berikut (Nugrahaningsih (2005) :

1. Sikap etis dalam mengerjakan tugas dengan kemampuan sendiri.

2. Tidak melanggar aturan dalam mengerjakan soal ujian.

3. Tidak menyuap atau mengancam dosen untuk meningkatkan nilai mata kuliah.

4. Mempersiapkan diri sendiri saat menghadapi soal ujian

\section{Variabel Independen,}

yaitu variabel yang memengaruhi atau yang menjadi sebab perubahannya atau timbulnya variabel dependen (Sugiyono (2009) Sugiyono, 2009). Variabel independen dalam penelitian ini terdiri dari: Love of money yang diukur dengan menggunakan metode yang dikembangkan oleh Tang and Chen (2008) yaitu Money Ethics Scale (MES) yang menggunakan 10 indikator, antara lainrichness, happiness, power of control, social influence, self expression, success, evil, danbudget.

\section{Populasi dan Teknik Penentuan Sampel}

Populasi dalam penelitian ini adalah mahasiswa reguler pagi Jurusan Akuntansi Fakultas Bisnis Universitas Triatma Mulya yang telah menempuh mata kuliah etika bisnis, yaitu mahasiswa semester 5 dan semester 7. Populasi difokuskan hanya pada mahasiswa reguler pagi, karena mahasiswa reguler pagi rata-rata belum pernah bekerja, sedangkan mahasiswa reguler sore rata-rata sudah bekerja. Pengalaman kerja yang dimiliki oleh mahasiswa tersebut kemungkinan akan mempengaruhi pandangan mahasiswa terhadap uang. Sehingga dalam penelitian ini hanya menggunakan mahasiswa reguler pagi yang belum pernah bekerja.Metode pengambilan sampel dilakukan dengan teknik sampling jenuh, dimana semua populasi digunakan sebagai sampel dalam penelitian.Adapun jumlah populasi dan sampel disajikan pada tabel 1.

[Table 1 about here.]

Sumber: Kemahasiswaan Fakultas Bisnis Universitas Triatma Mulya, 2019

\section{Teknik Analisis dan Pengumpulan Data}

Teknik analisis yang dipakai dalam penelitian ini adalah analisis regresi linier berganda. Sebelum menguji dan menganalisis data dengan menggunakan model analisis regresi linier berganda, maka terlebih dulu dilakukan pengujian asumsi klasik agar dapat dijadikan alat estimasi yang tidak bias jika telah memenuhi persyaratan BLUE (Best Linier Unbiased Estimator) sehingga hasil perhitungan dapat diinterpretasikan dengan efisien dan akurat.

Teknik pengumpulan data yang digunakan dalam penelitian ini adalah:

1. Wawancara, yaitu metode pengumpulan data dengan cara melakukan tanya jawab dengan Kepala Bagian Kemahasiswaan mengenai hal-hal yang terkait dengan responden penelitian, seperti jumlah mahasiswa Jurusan Akuntansi Fakultas Bisnis Universitas Triatma Mulya.

2. Kuesioner, yaitu metode pengumpulan data yang dilakukan dengan cara memberi seperangkat pertanyaan atau pernyataan tertulis kepada responden untuk dijawab (Sugiyono (2009) . Dalam penelitian ini digunakan skala likert dengan rentang 1 sampai 4 dengan alasan untuk menghindari jawaban-jawaban responden yang ambigu (bermakna ganda) karena adanya pernyataan "ragu-ragu" atau "netral" yang timbul dari nilai tengah (misal nilai 3 jika menggunakan 5 skala likert).

\section{HASIL DAN PEMBAHASAN}

Hasil Uji Validitas menunjukkan semua butir pernyataan kuesioner dalam penelitian ini valid karena masing-masing butir pernyataan dari variabel persepsi atas risiko, modal minimal investasi dan minat berinvestasi memiliki nilai koefisien korelasi $>0,3$. Uji Reliabilitas menunjukkan bahwa instrumen yang digunakan dalam penelitian ini adalah reliabel karena nilai cronchbach alpha masing-masing variabel dalam penelitian ini $>0,6$.

Pada tabel 2 ditampilkan hasil uji asumsi klasik yang merupakan syarat yang harus dipenuhi sebelum dilakukan uji regresi linier berganda.Hasil uji normalitas Kolmogorov 
Smirnov Test menunjukkan bahwa nilai Sig (2-Tailed) sebesar 0,911> dari Level of Significant $(0,05)$, sehingga dapat disimpulkan bahwa data dalam penelitian ini telah berdistribusi normal.Hasil uji multikolinieritas menunjukkan bahwa variabel Locus of Control dan Love of Moneymemiliki nilai VIF di bawah 10 dan nilai Tolerance diatas 0,10. Ini berarti tidak terjadi multikolinearitas antara variabel Locus of Control dan Love of Money.Hasil pengujian heteroskedastisitas menunjukkan bahwa nilai signifikansi variable Locus of Control dan Love of Money masing-masing memiliki nilai lebih besar dari Level of Significant $(0,05)$, sehingga bisa disimpulkan bahwa model tidak mempunyai masalah heteroskedastisitas.

[Table 2 about here.]

[Table 3 about here.]

Sumber: data diolah

Pengujian hipotesis pertama dilakukan untuk mengetahui pengaruh Locus of Control (LoC) terhadap perilaku etis mahasiswa akuntansi. Hasil pengujian dengan analisis regresi linier berganda pada Tabel 3 menunjukkan nilai signifikansi (Sig.t) variabel Locus of Control sebesar 0,006 lebih kecil dari $\alpha=$ $(0,05)$ dengan koefisien regresi sebesar 0,395 bertanda positif, yang artinya Locus of Control berpengaruh positif pada perilaku etis mahasiswa akuntansi Fakultas Bisnis Universitas Triatma Mulya, sehingga $\mathrm{H}_{1}$ diterima. Mahasiswa yang mampu mengendalikan sesuatu yang akan terjadi pada dirinya cenderung akan memiliki perilaku yang etis. Semakin kuat kemampuan mereka untuk mengendalikan kejadian yang terjadi pada dirinya, baik yang disebabkan oleh faktor internal maupun eksternal, akan semakin meningkatkan perilaku etis mahasiswa. Dengan kata lain, mahasiswa yang mampu mengendalikan takdir yang akan terjadi pada dirinya cenderung akan berperilaku etis. Hasil penelitian ini didukung oleh penelitian Uli et al. (2016) yang menyatakan bahwa Locus of Control berpengaruh terhadap Perilaku Auditor dalam Situasi Konflik Audit.Hasil penelitian ini juga didukung oleh penelitian Yovita and Rahmawaty (2016) yang menyatakan bahwa Locus of Controlberpengaruh terhadap perilaku etis Mahasiswa Akuntansi di Universitas Syiah Kuala.

Pengujian hipotesis kedua dilakukan untuk mengetahui pengaruh Love of Money terhadap perilaku etis mahasiswa akuntansi. Hasil pengujian analisis regresi linier berganda pada menunjukkan nilai signifikansi (Sig.t) variabel Love of Money sebesar 0,338 lebih besar dari $\alpha=(0,05)$. Hal ini berarti Love of Money tidak berpengaruhterhadap perilaku etis mahasiswa

\section{REFERENCES}

Agustini, A. T. (2016). Ethical Sensitivity and The Perception of Accounting Students: Is the Love of Money and Greed the Root of Unethical Attitudes. Accounting and Finance Review 1.

Arshinta, F., Djasuli, M., and Rimawati, Y. (2017). Faktor-Faktor yang Mempen- akuntansi di Fakultas Bisnis Universitas Triatma Mulya. Mahasiswa yang memiliki kecintaan terhadap uang (Love of Money) tidak akan mempengaruhi perilaku yang dilakukan oleh mahasiswa tersebut. Meskipun mereka memiliki sifat cinta terhadap uang, mereka tetap mempertahankan perilaku etis yang dimiliki.Hal ini mungkin karena mahasiswa menyadari bahwa perilaku tidak dapat dibeli dengan uang. Meskipun mereka dihadapkan pada nilai uang yang besar, mereka tetap akan mempertahankan perilaku etis yang dimiliki. Mahasiswa juga telah memperoleh mata kuliah etika dalam perkuliahan yang telah diresapi oleh mahasiswa itu sendiri, sehingga mereka tidak mempunyai niat untuk melakukan hal yang di luar aturan atau melawan norma. Di samping itu mahasiswa mungkin mulai memahami pentingnya peran sebagai seorang akuntan yang harus memiliki kode etik dalam menjalankan pekerjaannya dan menjaga nama baik sebagai seorang akuntan.

Hasil penelitian ini tidak sesuai dengan penelitian Novitasari and Sukirno (2010) yang menyatakan bahwa Love of Money berpengaruh negatif dan signifikan terhadap persepsi etis mahasiswa akuntansi Universitas Negeri Yogyakarta.Namun hasil penelitian ini didukung oleh penelitian R.Rindayanti and Budiarto (2017) yang menyatakan Love of Money tidak berpengaruh signifikan terhadap perilaku etis mahasiswa akuntansi.

\section{KESIMPULAN}

Hasil yang diperoleh dalam penelitian ini adalah Locus of Control berpengaruh positif terhadap perilaku etis mahasiswa akuntansi Fakultas Bisnis Universitas Triatma Mulya dengan nilai signifikansi sebesar 0,006.Sedangkan Love of Money tidak berpengaruh terhadap perilaku etis mahasiswa akuntansi Fakultas Bisnis Universitas Triatma Mulya, yang mungkin disebabkan karena mahasiswa lebih menjunjung perilaku etis meskipun mereka memiliki sikap cinta terhadap uang.

Akhir kata penulis menyampaikan terima kasih kepada semua pihak yang telah membantu dalam menyelesaikan penelitian ini.Semoga penelitian ini dapat bermanfaat bagi perkembangan ilmu pengetahuan, khususnya akuntansi dan juga dapat diaplikasikan dalam kehidupan nyata.

\section{UCAPAN TERIMA KASIH}

Peneliti mengucapkan terima kasih kepada rekan-rekan Fakultas Bisnis, Universitas Triatma Mulya yang telah memberikan dukungan sehingga dapat menyelesaikan artikel ini. garuhi Persepsi Etika Mahasiswa Akuntansi dengan Love of Money sebagai Variabel Intervening. Jurnal Keuangan dan Perbankan 13.

Basri, Y. M. (2015). Pengaruh Gender, Religiusitas dan Sikap Love of Money pada Persepsi Etika Penggelapan Pajak Mahasiswa Akuntansi. Jurnal Ilmiah Akuntansi dan Bisnis 10.

Bulutobing, L. and Paramitasari, R. D. A. (2017). Pengaruh Sifat Machiavellian dan 
Love of Money terhadap Perilaku Etis Auditor. Jurnal Ilmiah Akuntansi Peradaban 3.

Febrianty (2010). Pengaruh Gender, Locus of Control, Intellectual Capital, dan Ethical Sensitivity terhadap Perilaku Etis Mahasiswa Akuntansi pada Perguruan Tinggi (Survey pada Perguruan Tinggi di Kota Palembang). Jurnal Ilmiah Orasi Bisnis. Edisi IV.

Himmah, E. F. (2013). Persepsi Etis Mahasiswa Akuntansi Mengenai Skandal Etis Auditor dan Corporate Manager. Jurnal Akuntansi Multiparadigma 4.

Khoiriyah, S. L. (2013). Analisis Faktor Personal dan Pertimbangan Etis terhadap Perilaku Auditor pada Situasi Konflik Audit. Accounting Analysis Journal 2.

Manuari, I. A. R., Mimba, N. P. S. H., and Dwirandra, A. A. N. B. (2018). The Effect of Love of Money on Ethizs with Manacika Parisudha (Concept of Good Thinking) as Moderating Variables. International Journal of Economics, Commerce and Management 6.

Nikara, I. I. K. and Mimba, N. (2019). Pengaruh Love of Money, Machiavellian, Idealisme dan Religiusitas pada Persepsi Etis Mahasiswa Akuntansi.E-Jurnal Akuntansi Universitas Udayana. E-Jurnal Akuntansi Universitas Udayana 26.

Novitasari, E. D. and Sukirno (2010). Pengaruh Love of Money dan Perilaku Machiavellian terhadap Persepsi Etis Mahasiswa Akuntansi (Studi Kasus pada Mahasiswa S1 Program Studi Akuntansi Angkatan. Jurnal Profita. 3.

Nugrahaningsih, P. (2005). Analisis Perbedaan Perilaku Etis Auditor di KAP dalam Etika Profesi (Studi Terhadap Peran Faktor-Faktor Individual :Locus of Control, Lama Pengalaman Kerja, Gender, dan Equity Sensitivity. In SNA VIII Solo, 617630, ed. and others. 617-630.

Pradanti, N. R. and Prastiwi, A. (2014). Analisis Pengaruh Love of Money terhadap Persepsi Etis Mahasiswa Akuntansi. Diponogoro Journal of Accounting 3.

R.Rindayanti and Budiarto, D. S. (2017). Hubungan antara Love of Money, Machiavellian dengan Persepsi Etis: Analisis Berdasarkan Perspektif Gender. Akuntabilitas: Jurnal Ilmu Akuntansi 10.

Sugiantari, N. K. and Widanaputra, A. (2016). . Pengaruh Idealisme, Relativisme, dan Love of Money pada Persepsi Mahasiswa Akuntansi tentang Krisis Etika Akuntan. E-Jurnal Akuntansi Universitas Udayana 17.

Sugiyono (2009). Metode Penelitian Bisnis (Bandung: Alfabeta).
Tang, T. L. P. and Chen, Y. J. (2008). Inteleligence vs Wisdom: The love of Money, Machiavellianism and Unethecial Behavior Across College Major and Gender. Journal of Business And Ethic 82, 1-26.

Uli, A. S., Tanjung, A. R., and Paulus, S. (2016). Pengaruh Locus of Control, Pengalaman Auditor dan etika Profesional terhadap Perilaku Auditor dalam Situasi Konflik Audit. JOM FEKON 3.

Widiani, N. P., Putri, A. M. A. D., Sari, M. M. R., and Wirajaya, I. G. A. (2019). The Effect of Love of Money and Emotional Intelligence on Employee Performance with Organizational Citizenship Behavior as Mediating Variable. International Research Journal of Engineering, IT \& Scientific Research 5.

Yendrawati, R. and Witono (2011). Pengaruh Sifat Machiavellian, Locus Of Control, Dan Independensi Terhadap Perilaku Etis Auditor (Studi Empiris Pada Kantor Akuntan Publik Di Yogyakarta). Jurnal Aplikasi Bisnis 10.

Yovita, C. S. D. and Rahmawaty (2016). Pengaruh Gender, Ethical Sensitivity, Locus of Control, dan Pemahaman Kode Etik Profesi Akuntan terhadap Perilaku Etis Mahasiswa Akuntansi Universitas Syiah Kuala. Jurnal Ilmiah Mahasiswa Ekonomi Akuntansi (JIMEKA) 1.

Yusuf, H. M. and Anim, W. (2015). Analysis of Effect of Ethics Education and Love of Money Perception of Accounting Students in the Preparation of Financial Statements. Journal of Education and Vocational Research. 6.

Conflict of Interest Statement: The author declare that the research was conducted in the absence of any commercial or financial relationships that could be construed as a potential conflict of interest.

Copyright () 2019 Author. This is an open-access article distributed under the terms of the Creative Commons Attribution License (CC BY). The use, distribution or reproduction in other forums is permitted, provided the original author(s) and the copyright owner(s) are credited and that the original publication in this journal is cited, in accordance with accepted academic practice. No use, distribution or reproduction is permitted which does not comply with these terms. 


\section{LIST OF TABLES}

Jumlah Sampel . . . . . . . . . . . . . . . . . . . . . . . . . . . . . . . . . . . . 108

Hasil Uji Asumsi Klasik . . . . . . . . . . . . . . . . . . . . . . . . . . . . . . . . . . . . . . . . . . . . . . . . 109

Hasil Analisis Data _ . . . . . . . . . . . . . . . . . . . . . . . . . . . . . . 110 
TABLE 1 | Jumlah Sampel

Keterangan Jumlah

Mahasiswa akuntansi semester 5

Mahasiswa akuntansi semester 7

Jumlah Sampel
21 orang

38 orang 
TABLE 2 | Hasil Uji Asumsi Klasik

\begin{tabular}{lll}
\hline Keterangan & Indikator & \\
Uji Normalitas & Sig (2-Tailed) & 0.911 \\
Uji Multikolinieritas & Tolerance X1 & 0,510 \\
& Tolerance X2 & 0,510 \\
& VIP X1 & 1,960 \\
& VIP X2 & 1,960 \\
Uji Heteroskedastisitas & X1 & 0.772 \\
& X2 & 0.810 \\
\hline
\end{tabular}


TABLE 3 | Hasil Analisis Data

\begin{tabular}{|c|c|c|c|c|c|c|}
\hline \multirow[t]{3}{*}{ Model } & & $\begin{array}{l}\text { Unstandardized } \\
\text { Coefficients }\end{array}$ & & $\begin{array}{l}\text { Standardized } \\
\text { Coefficients }\end{array}$ & $t$ & Sig. \\
\hline & & & Std. Error & Beta & & \\
\hline & (Constant) & 12.527 & 3.596 & & 3.484 & .001 \\
\hline HoC & .395 & .135 & .604 & 2.917 & .006 & \\
\hline LoM & -.102 & .105 & -.201 & -.971 & .338 & \\
\hline
\end{tabular}

